\title{
Present status of renal replacement therapy in Asian countries as of 2016: Cambodia, Laos, Mongolia, Bhutan, and Indonesia
}

\author{
Toru Hyodo ${ }^{1 *}$, Masafumi Fukagawa ${ }^{1}$, Nobuhito Hirawa ${ }^{1}$, Matsuhiko Hayashi ${ }^{1}$, Kosaku Nitta ${ }^{2}$, Sovandy Chan $^{3}$, \\ Phanekham Souvannamethy ${ }^{4}$, Minjur Dorji ${ }^{5}$, Chuluuntsetseg Dorj ${ }^{6}$ and I. Gde Raka Widiana ${ }^{7,8}$
}

\begin{abstract}
Since 2015, the Committee for International Communication on Academic Research of the Japanese Society for Dialysis Therapy has held its Asian symposium during the society's Annual Congress to discuss the present status of and demand for dialysis therapy in Asian countries in order to identify needs and find ways to contribute to these countries in the area of dialysis therapy. Five manuscripts are presented here by symposium participants from Cambodia, Laos, Bhutan, Mongolia, and Indonesia from the Asian symposium of 2016.

With progress in economic development, hemodialysis (HD) therapy has now been introduced in all countries worldwide. However, the cost of HD is extremely high compared with typical incomes in every country, and as of 2016, many countries still have not established national health insurance systems. In Cambodia and Laos, for example, patients must bear $100 \%$ of the cost for dialysis. In contrast, in Bhutan, the government bears all costs and the patients need not pay at all. In Mongolia and Indonesia, dialysis is almost completely covered by national health insurance. Dialyzers tend to be reused in Cambodia, Laos, and Indonesia. In Mongolia and Bhutan, dialyzers are single-use only. Continuous ambulatory peritoneal dialysis is available in Mongolia and Indonesia but is just starting to be introduced in Laos; it is not available in Cambodia and Bhutan. In Cambodia and Laos where there is no national health insurance system, patients with lower socioeconomic status come to the HD center only when they have enough money to pay for an HD session. Viable health insurance systems should be established as soon as possible. However, this will ultimately depend on the countries' economic development.
\end{abstract}

Keywords: Committee of International Communication for Academic Research of the Japanese Society for Dialysis Therapy, Asian developing countries, Dialysis therapy, Cambodia, Khmer Rouge-controlled state, Hemodialysis, National health insurance system, Economic development, Lao People's Democratic Republic, Bhutan, Kidney transplantation, Chronic kidney disease, Healthcare program, Mongolia, Peritoneal dialysis, Japan, Dialysis nurses, Dialysis doctors, Clinical engineers

\section{Preface}

Toru Hyodo, Masafumi Fukagawa, Nobuhito Hirawa, Matsuhiko Hayashi, Kosaku Nitta, Japan

Recently, developing countries in Asia are showing marked economic progress and rapid growth in terms of information and communications technology. These technologies allow physicians in these countries, as well the general populace, to learn in real time about the latest

\footnotetext{
* Correspondence: thyodomd@gmail.com

${ }^{1}$ The Committee of International Communication for Academic Research of the Japanese Society for Dialysis Therapy, Tokyo, Japan

Full list of author information is available at the end of the article
}

treatments provided in developed countries. As a result, there is a rapidly growing demand for healthcare services of the same standard as those available in developed countries. People now know that diseases deemed incurable in their home countries can now be treated with advanced methods in developed countries. Dialysis therapy is a typical example. Since 2015, the Committee of International Communication for Academic Research of the Japanese Society for Dialysis Therapy (JSDT) has held the first and second Asian symposia to discuss the present status of and demand for dialysis therapy in Asian countries in order to identify how to contribute to these countries in

(c) The Author(s). 2019 Open Access This article is distributed under the terms of the Creative Commons Attribution 4.0 International License (http://creativecommons.org/licenses/by/4.0/), which permits unrestricted use, distribution, and reproduction in any medium, provided you give appropriate credit to the original author(s) and the source, provide a link to the Creative Commons license, and indicate if changes were made. The Creative Commons Public Domain Dedication waiver (http://creativecommons.org/publicdomain/zero/1.0/) applies to the data made available in this article, unless otherwise stated. 
the area of dialysis therapy. The first symposium covered Myanmar, Vietnam, Thailand, China, and Japan. In this second symposium, issues from Cambodia, Laos, Bhutan, Mongolia, and Indonesia were introduced.

We hope this report will be helpful in activities to provide support from developed to developing countries.

\section{Renal replacement therapy in Cambodia}

Chan Sovandy, Cambodia

\section{History of Cambodia's medical system after World War II}

The medical system in Cambodia after World War II (1939-1945) improved considerably during the period of French colonialization with the introduction of modern medicine. Under the Sangkum Reastr Niyum (19531970), the political organization established by King Sihanouk, huge accomplishments were made in Cambodia's medical system by establishing many public hospitals, such as Calmette Hospital and the Khmer-Soviet Friendship Hospital. However, under Democratic Kampuchea (1975-1979), the Khmer Rouge-controlled state, the medical system in Cambodia was dismantled as part of efforts to isolate the country from foreign influences. The system collapsed so extensively that people had to resort to using natural and herbal medication; for instance, coconut water was used for fluid replacement instead of physiological saline.

Today, Cambodia has a multiparty democracy under a constitutional monarchy (1993-present), and the entire medical system has been revamped. However, it is not up to global standards due to the shortage of experts, lack of education and experience, and poverty.

\section{History of hemodialysis in Cambodia}

Between 1998 and 2007, there was only one dialysis center (Calmette Hospital) in Cambodia, and many patients with end-stage renal disease (ESRD) had to go to Thailand or Vietnam (Ho Chi Minh City) to receive hemodialysis (HD). From 2007 to 2010, four dialysis centers were established in Cambodia. In March 2010, the Cambodia-Japan Friendship Blood Purification Center was established in Sen Sok International University Hospital. The general public has become aware of HD therapy from regular widespread health education television programs made by this University Hospital.

As of 2016, there are eight HD centers in Cambodiasix in Phnom Penh and one each in the provinces of Battambang and Siem Reap. The total number of HD patients is estimated at around 300 to 500 patients (no statistical data are as yet available in Cambodia as of 2016). People living in Phnom Penh earn an average of 150 USD per month. However, HD costs are between 45 and 60 USD per session. This includes the cost for dialyzer-reuse HD, where dialyzers are reused up to 6 times. Patients are responsible for all medical costs because there is no health insurance system in Cambodia. This means that HD is available to only people of higher socioeconomic status. Due to the history of genocide that took place under the Khmer Rouge regime (people were killed in the process of telling on one another), Cambodian people therefore tend to be mistrustful of each other. Besides the struggling economy, this may be a major barrier to establishing a viable health insurance system in Cambodia.

\section{Case report}

A 56-year-old woman with a diagnosis of ESRD and no history of diabetes mellitus started HD. She was given a diagnosis of ESRD in late November 2014. A local physician recommended HD, but it was not performed because of the cost; she worked as a gardener, and her monthly income was just 79 USD. She lived in Phnom Penh but had difficulty even getting to the dialysis center because there is no public transportation in the city. However, her neighbors and relatives found out through a health education television program made by Sen Sok International University Hospital that ESRD patients can survive by undergoing $\mathrm{HD}$ and that it was available in Cambodia. They raised enough money for her to receive HD. By the end of December 2014, approximately 1500 USD had been donated. This case was presented at the 3rd Annual Meeting of the Japanese Society of Renal Nutrition and Metabolism by Ms. Rith Susan and Ms. Thim Pich Thida, medical students at International University, Phnom Penh, Cambodia, under the title "The sign toward the establishment of an insurance system in Cambodia." However, this beautiful story did not continue for long as the patient died in late July 2015. She started coming to the HD center less frequently, visiting every 10 days. When Dr. Yim Sovannbophea of Cambodia-Japan Friendship Blood Purification Center of Sen Sok International University Hospital called her on the phone because more than 14 days had passed since her last HD session, she had sounded weak and said in a faint voice that she had given up on HD because she chose not to burden her neighbors and relatives anymore.

\section{Discussion and future challenges}

The importance of money and financial resources for healthy living cannot be overemphasized and can be summed up in the phrase "No money, no life." The law of natural selection holds sway in developing countries that do not have health insurance systems. Patients of lower socioeconomic status come to the HD center only when they have enough money to pay for an HD session. The author has encountered numerous cases where patients had to receive conservative therapy because they lacked money to pay for HD therapy. The cost of one HD session is about 45 to 60 USD, while the average monthly salary is 150 USD. HD therapy is thus impossible for the general 
Cambodian populace to access. This is the sad reality. A viable health insurance system should be established as soon as possible. However, this will ultimately depend on the country's economic development.

We also have other problems to overcome. Very few doctors have the required training and experience in HD. Currently, there are only 15 dialysis doctors or nephrologists in Cambodia and few dialysis nurses. There are no clinical engineers to manage dialysis machines and patients, and there are no dietitians to provide guidance for dietary therapy. There are also no training programs in place to develop these medical professionals.

The major need of renal replacement therapy (RRT) in Cambodia is educational systems, with training programs that can facilitate the development of dialysis doctors and other specialists. Health insurance should also be established to support the management of patients with ESRD.

\section{Acknowledgements}

Special thanks to Ms. Rith Susan and Ms. Thim Pich Thida, medical students of International University, Phnom Penh, Cambodia, for their cooperation in collecting the data presented in this manuscript. Thanks also to Dr. Yim Sovannbophea, Cambodia-Japan Friendship Blood Purification Center, Phnom Penh, Cambodia.

\section{Renal replacement therapy in Lao People's Democratic Republic}

Phanekham Souvannamethy

\section{Background}

Lao People's Democratic Republic (PDR) is a land-locked country located in the heart of the Indochina Peninsula of Southeast Asia, bordered by Cambodia to the south, China to the north, Vietnam to the east, Thailand to the west, and Myanmar to the northwest. The country covers 236,800 $\mathrm{km}^{2}$, stretching $1700 \mathrm{~km}$ from north to south and $500 \mathrm{~km}$ from east to west at the widest point, and has a population of approximately 7,000,000. The capital city is Vientiane, and the official currency is the kip. Regarding religion, $55 \%$ of the total population are Buddhists, 35\% Animists, and 10\% of other faiths. Almost $40 \%$ of the population live in poverty and $26 \%$ live on less than 1 USD per day. Only half of the population are literate. The country is run by a single party, the Lao People's Revolutionary Party. Ethnically, $60 \%$ of the population is Lao and $40 \%$ are minority ethnic groups.

Regarding the background of dialysis therapy, the cost of HD is 55-60 USD per session and only 5 HD sessions are covered by the country's national health insurance. Patients must cover the cost after five sessions by themselves. Dialyzers are reused (10 to 12 times). Preparations for the introduction of continuous ambulatory peritoneal dialysis (CAPD) are in the initial stages. There are no dietitians or clinical engineers in our country.

\section{History and present status of Mittaphab Hospital Dialysis Center}

The Mittaphab Hospital Dialysis Center was established as a dialysis unit in 1989 with the support of the Vietnamese government (Fig. 1a). However, the center was closed from 1993 to 1997, but reopened in 1998 with support from the Japan International Cooperation Agency (JICA), Lao Compatriots Association, and the Nephrology Society of Thailand. At the end of 2011, the HD unit was upgraded to the current dialysis center and a new ward was attached (Fig. 1b). As of 2015, the center also received support from a medical corporation of Japan (Fig. 1c-d). As of 2016, the dialysis center was manned by 7 doctors, 3 interns, 15 nurses ( 8 on the ward, 7 in the dialysis room), and 1 hospital housekeeper. We now have $16 \mathrm{HD}$ machines and 4 on-line HDF consoles. The number of outpatients in the Nephrology Department of Mittaphab Hospital is shown in Table 1. Demographic data of patients treated on the nephrology ward are shown in Table 2 . The total number of dialysis sessions by year and by sex are shown in Table 3 . Table 4 shows the number of vascular access surgeries performed, with the number increasing from 11 in 2012 to 98 cases in 2015. Some ESRD patients in Laos visit other countries like Thailand and Vietnam to start dialysis therapy. They then come back and receive maintenance HD in Laos. Therefore, we have expertise in reconstructive operations for vascular access created in other countries. The number is noted in parentheses; 5(2) means that the total number of reconstructive operations is 5 , of which the number of reconstructive operations for vascular access created in other countries is 2 . The highest number of dialysis sessions in our dialysis center was in 2014. The longest dialysis vintage among our patients is 15 years. We also have some pediatric dialysis patients.

\section{Future challenges}

There is currently no health insurance system in our country because of the ailing economy. Thus, patients cannot undergo $\mathrm{HD}$ regularly due to monetary constraints. Other major hindrances to education and awareness for preventing chronic kidney disease (CKD) are the high poverty rate and low level of literacy. Nevertheless, the number of patients with ESRD has been increasing recently. There are very few nephrologists $(<10)$, and dialysis equipment and infrastructure are sorely lacking. There is a dire need for more specialist nephrologists and dialysis nurses, as well as infrastructure for HD therapy in Lao PDR. We also need transplant surgeons and nurses, laboratories, and a renal bank for transplant surgery. Measures should be taken to resolve these issues step by step.

Finally, we are preparing to establish the Laos Society of Nephrology in cooperation with volunteers of the Japanese Society for Dialysis Therapy and the Nephrology Society of Thailand. We plan to construct a Laos Dialysis Registry 

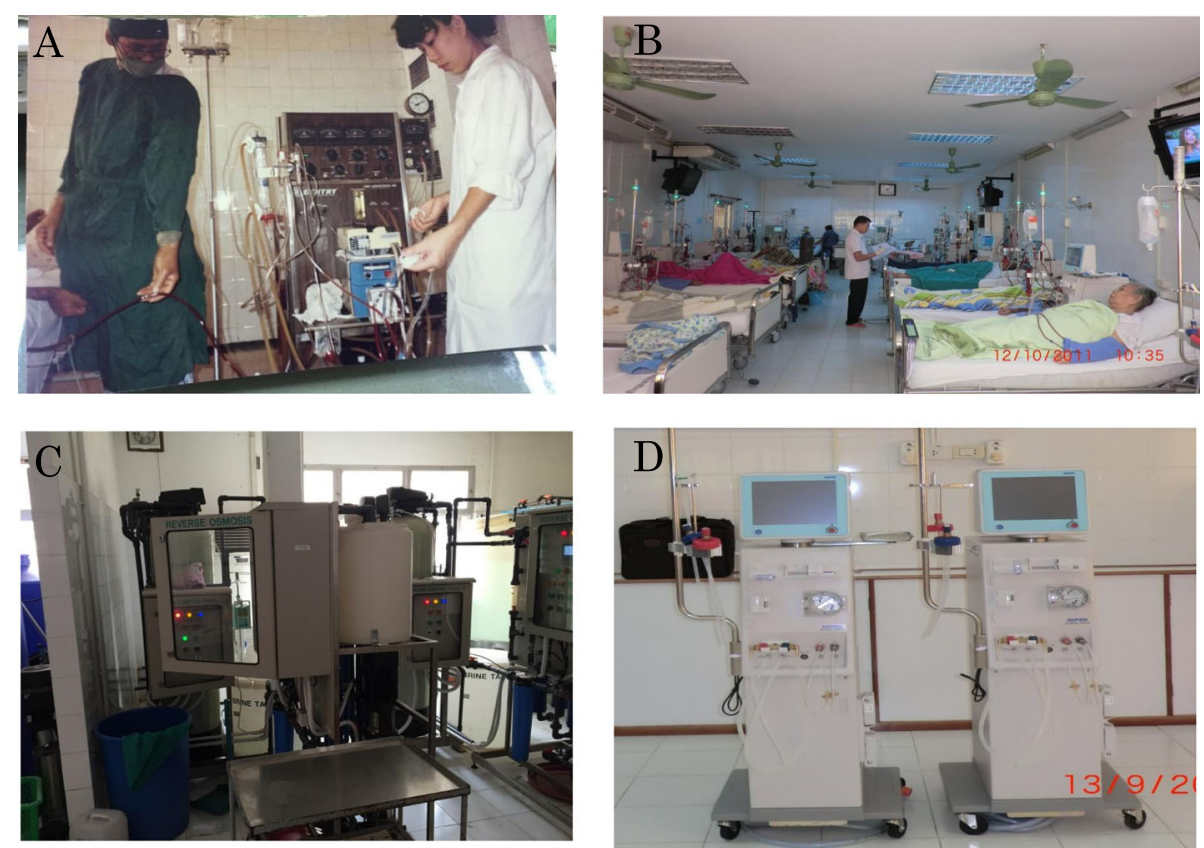

Fig. 1 a The first hemodialysis machine in Laos introduced by Vietnamese nephrologists. b Dialysis center scene in 2016. c Reverse osmosis water supply system in 2016. d Dialysis consoles in 2016

database to clarify and elucidate the present status of ESRD in Laos. The prevalence and incidence of dialysis, cause of ESRD, and mortality will be clarified in the near future.

\section{Current needs of renal replacement therapy in Bhutan}

Minjur Dorji, MD

\section{History of dialysis therapy in Bhutan}

There are currently three HD centers in Bhutan serving a population of about 0.7 million. The HD center at Jigme Dorji Wangchuck National Referral Hospital (JDWNRH) is one of these centers. It was established in 1998, and HD was introduced with two patients and two dialysis console units following the successful 3-month HD training of a Bhutanese physician in another country. The other two HD centers, the Mongar Regional Referral Hospital and Gelephu Regional Referral Hospital, were established in 2011. As of 2016, there were 150 patients with ESRD and 18 HD consoles in all three HD centers.

Table 1 Number of outpatients in the nephrology department of Mittaphab Hospital

\begin{tabular}{llll}
\hline Year & Male (\%) & Female (\%) & Total \\
\hline 2012 & $516(56.5)$ & $397(43.5)$ & 913 \\
2013 & $844(57.8)$ & $617(42.2)$ & 1461 \\
2014 & $735(50.6)$ & $718(49.4)$ & 1453 \\
2015 & $568(49.5)$ & $579(50.5)$ & 1147 \\
\hline
\end{tabular}

The cost of HD is supported by the government. Dialyzers are reused up to three times in HD cases without HIV or hepatitis A and C but are single-use for infected patients. CAPD is not yet available.

\section{Current status of renal replacement therapy in Bhutan: a single-center retrospective study \\ Purpose}

There is currently no statistically relevant study of ESRD patients in Bhutan. Therefore, we retrospectively analyzed ESRD patients treated in our HD center at JDWNRH, Thimphu, Bhutan.

Table 2 Number, hometown, and diseases of patients treated in the nephrology ward of Mittaphab Hospital

\begin{tabular}{lllll}
\hline Year & 2012 & 2013 & 2014 & 2015 \\
\hline Male & 302 & 501 & 496 & 627 \\
Female & 413 & 569 & 636 & 576 \\
Total number & 715 & 1070 & 1132 & 1203 \\
Capital city & 459 & 744 & 735 & 760 \\
Provinces & 256 & 326 & 397 & 443 \\
Diabetes mellitus & 89 & 60 & 51 & 34 \\
Nephrosclerosis & 23 & 39 & 22 & 19 \\
Urinary tract infection & 24 & 13 & 12 & 12 \\
Acute kidney disease & 18 & 45 & 39 & 47 \\
Chronic kidney disease & 367 & 503 & 423 & 393 \\
Others & 29 & 74 & 93 & 106 \\
\hline
\end{tabular}


Table 3 Total number of dialysis sessions by year and sex in Mittaphab Hospital Dialysis Center

\begin{tabular}{llll}
\hline Year & Male (\%) & Female (\%) & Total \\
\hline 2012 & $3022(51.8)$ & $2817(48.2)$ & 5839 \\
2013 & $4042(50.2)$ & $4010(49.8)$ & 8052 \\
2014 & $4837(50.2)$ & $4806(49.8)$ & 9643 \\
2015 & $2643(52.2)$ & $2424(47.8)$ & 5067 \\
\hline
\end{tabular}

\section{Materials and methods}

Data from 1998 to 2015 were collected, and the incidence, age, sex, causes of ESRD, and hometown of patients were analyzed.

\section{Results}

In total, 610 ESRD patients needed RRT. The yearly incidence rate increased 50-fold, from 2.86 patients per million in 1998 to 144.29 in 2015. Patients numbers according to the location of their hometowns were 43 (7\%) in Central Bhutan, 214 (35\%) in East Bhutan, 140 (23\%) in West Bhutan, and 213 (35\%) in South Bhutan. The age distribution is shown in Table 5. The peak of distribution was in young persons aged $31-50$ years. Males comprised 338 cases (54.43\%) and females 272 (45.57\%). The causes of ESRD are shown in Table 6. The majority of cases were of unknown etiology. Diabetes mellitus was the fourth leading cause, but it was not the primary disease. In total, 155 (25\%) ESRD patients received kidney transplants and 455 (75\%) patients underwent HD.

\section{Discussion}

The incidence rate of ESRD has been drastically increasing, with most patients aged $31-50$ years, which marks the most productive years of life. This has a negative impact on individuals, society, and the country at large. To reduce the progression of CKD to ESRD nationwide, it is necessary to develop a better healthcare program to prevent CKD and ensure timely detection in the early stages. However, Bhutan is still a developing country where medical and other resources are limited and infrastructure is inadequate. More HD machines and related equipment, including peritoneal dialysis

Table 4 Number of patients who received vascular access surgeries in Mittaphab Hospital Dialysis Center

\begin{tabular}{lllll}
\hline Year & 2012 & 2013 & 2014 & 2015 \\
\hline Short-term catheter & $5(2)$ & $8(3)$ & $15(4)$ & $18(2)$ \\
Permanent catheter & $2(0)$ & $4(1)$ & $4(1)$ & $7(2)$ \\
Arteriovenous fistula (AVF) & & & & \\
$\quad$ Radiocephalic AVF & $3(2)$ & $4(2)$ & $31(2)$ & $39(3)$ \\
$\quad$ Brachiocephalic AVF & $1(0)$ & $12(4)$ & $41(1)$ & $34(1)$ \\
Total number & $11(9)$ & $28(10)$ & $91(8)$ & $98(8)$ \\
\hline
\end{tabular}

Data indicated in parentheses are the number of the reconstructive operations for vascular access made in other countries
Table 5 Number and age distribution of HD patients in the JDWNRH HD center, Thimphu, Bhutan

\begin{tabular}{ll}
\hline Age (years) & Number (\%) \\
\hline$<15$ & $6(1)$ \\
$15-30$ & $134(22)$ \\
$31-50$ & $220(36)$ \\
$50-70$ & $195(32)$ \\
$>70$ & $55(9)$ \\
\hline
\end{tabular}

(PD) fluids and accessories, are needed to manage the increasing number of ESRD patients. Financial assistance, especially from advanced countries, is also important.

\section{Conclusion}

A comprehensive action plan is needed to reduce the increasing number of ESRD patients and to provide more HD machines for treatment.

\section{History and present status of renal replacement therapy in Mongolia}

Chuluuntsetseg Dorj, MD and Clinical Professor

\section{Background}

Mongolia has an estimated population of 3,000,000 as of 2015 , with a total land area of $1,564,116 \mathrm{~km}^{2}$. The capital city of Ulaanbaatar alone has a population of 1,300,000 as of 2015. Figure 2 shows the five major diseases in Mongolia, with genitourinary diseases rated third among them. RRT in Mongolia began with the introduction of HD in 1975, kidney transplantation in 1996, and PD in 2014. Table 7 shows the patient numbers of these therapies since 2007. The history of RRT is synonymous with that performed at the First Central Hospital of Mongolia.

\section{RRT in Mongolia}

Kidney transplantation therapy in Mongolia

The first kidney transplantation was performed from a living donor in 1996 at the First Central Hospital of Mongolia in collaboration with a foreign renal transplant team. A domestic transplant team was formed in the same year and received training overseas until 2005. Since 2006, the team has successfully performed kidney transplantation independently. The first retransplantation

Table 6 Causes of ESRD in the JDWNRH HD center, Thimphu, Bhutan

\begin{tabular}{ll}
\hline Causes & Number (\%) \\
\hline Undetermined & $242(40)$ \\
Hypertensive nephrosclerosis & $172(28)$ \\
Chronic glomerulonephritis & $86(14)$ \\
Diabetic nephropathy & $80(13)$ \\
Others & $30(5)$ \\
\hline
\end{tabular}




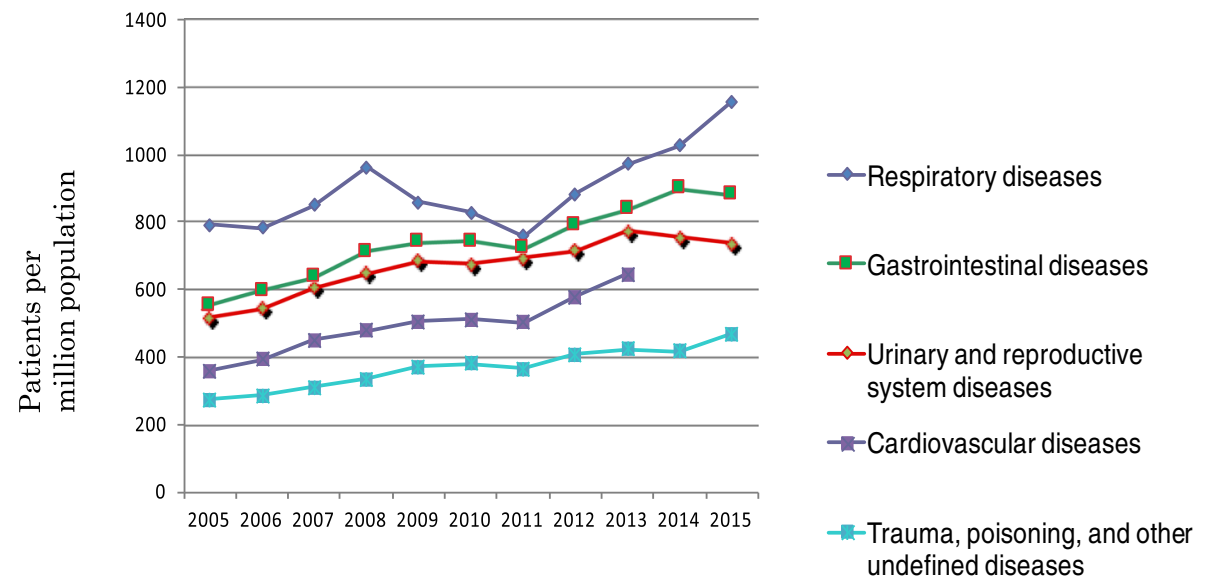

Fig. 2 The five major diseases in Mongolia. Genitourinary diseases are rated third

was performed successfully in May 2016. Among 203 cases of kidney transplantation, 123 were performed by the domestic transplant team. Thirteen cases were cadaveric donor transplants. Table 8 shows the number of kidney transplantations from living donors performed in Mongolia and foreign countries since 1996. Table 9 shows the demographic data (age and sex) of kidney transplant patients treated by the domestic transplant team.

\section{$P D$ in Mongolia}

PD was first introduced in 2014. Currently, nine patients are receiving PD treatment, one of whom has received a kidney transplant. The PD solutions used are produced by a domestic manufacturer (IVCO LLC, Ulaanbaatar, Mongolia).

\section{$H D$ in Mongolia}

The first HD professionals were trained in Moscow in 1974, and HD was first introduced in 1975. The first HD facility had 2-4 machines and was affiliated with the Nephrology Department. On June 1, 2006, it was upgraded to an HD center.

\section{Japan's support for dialysis in Mongolia}

Japan has contributed tremendously to the development of dialysis therapy to its current levels in Mongolia. Specifically, the Tokushukai Medical Group has recently provided support in the form of donated HD equipment, personnel training, and foundation-laying for building three new HD units. Through the financial investment by

Table 7 Patient numbers of RRT in First Central Hospital of Mongolia since 2007

\begin{tabular}{llllllllll}
\hline Year & 2007 & 2008 & 2009 & 2010 & 2011 & 2012 & 2013 & 2014 & 2015 \\
\hline PD & 0 & 0 & 0 & 0 & 0 & 0 & 0 & 2 & 8 \\
Tx & 8 & 25 & 26 & 30 & 32 & 8 & 12 & 18 & 13 \\
HD & 36 & 68 & 91 & 113 & 154 & 163 & 164 & 154 & 154 \\
\hline
\end{tabular}

the Group, three HD centers were established in Mongolia. Tokuda Torao Dialysis Center was established at the First Central Hospital in 2011 with ten dialysis console units. The center currently treats 45-60 HD patients using 14 consoles in all. The other two HD centers were established in Bayankhongor province in December 2015 and in Nalaikh town in March 2016, respectively, with five machines each. They treat up to $60 \mathrm{HD}$ patients each.

Japan has also contributed immensely in the area of training programs for doctors, nurses, and technicians. In 2011 and 2012, dialysis doctors and nurses attended a 1-month training at Tokushukai Medical Group hospitals in Japan. In addition, two other doctors have attended a 3-month course at the Saiseikai Yahata General Hospital in Fukuoka, Japan.

Nipro Corporation, the Japanese global manufacturer of renal and dialysis products, has also contributed to HD services in Mongolia. Nipro's staff visit dialysis units across Mongolia and perform regular maintenance checks of HD systems. Around $60 \%$ of the HD machines currently in use are manufactured by Nipro. The local manufacturing company IVCO and Nipro collaborate closely to ensure consistent operation of the HD machines. Mongolian engineers from IVCO have also visited Japan and completed training in the maintenance of HD systems. As a result, Mongolian engineers have mastered the latest maintenance methods to keep HD systems operating maximally. This is an important contribution by a Japanese company to nurturing clinical engineering human resources in Mongolia.

The supply of HD machines has improved over time, and 485 patients with ESRD are now receiving HD treatment (Table 10). As of 2016, there were 13 HD units, with 122 consoles in total, located in the capital city and provinces.

\section{Future issues}

It is expected that more than 100-140 new ESRD patients per year will need HD in Mongolia. The HD centers 
Table 8 Number of living donor kidney transplantation in Mongolia and other countries

\begin{tabular}{|c|c|c|c|c|c|c|c|c|c|c|c|c|c|c|c|c|c|c|c|c|c|}
\hline & 1996 & 1997 & 1998 & 1999 & 2000 & 2001 & 2002 & 2003 & 2004 & 2005 & 2006 & 2007 & 2008 & 2009 & 2010 & 2011 & 2012 & 2013 & 2014 & 2015 & Total \\
\hline China & & & 1 & 2 & & 5 & & 7 & 6 & 16 & 2 & 1 & 3 & & & & & & 1 & & 43 \\
\hline Korea & & & & & & & & & & & & & & 2 & 3 & 9 & 7 & 13 & 10 & 1 & 45 \\
\hline Pakistan & & & & & & & & & & & & & 1 & & & & & & & & 1 \\
\hline Hungary & & & & & & & & & & & 1 & & & & & & & & & & 1 \\
\hline Japan & & & & & & & & & & & & & & 1 & & & & & & & 1 \\
\hline India & & & & & & & & & & & & & & & & & 1 & & & 1 & 2 \\
\hline Mongolia & 1 & & & & & & & & & & 8 & 5 & 14 & 11 & 11 & 9 & 7 & 12 & 18 & 14 & 110 \\
\hline Total & & & & & & & & & & & & & & & & & & & & & 203 \\
\hline
\end{tabular}

currently have between 80 and 100 consoles, but there is a dire need for specialists with expertise in dialysis machine maintenance (clinical engineers), as well as dialysis nurses and doctors. It is necessary to establish a system for training such dialysis specialists. Furthermore, medications needed to prevent the development of secondary dialysis complications remains a challenge. The health insurance system, beyond the state budget, should therefore become involved in easing the burden of expenditures for HD therapy.

\section{Economic burden of dialysis in Indonesia: what do we need?}

I Gde Raka Widiana

Division of Nephrology and Hypertension, Sanglah General Hospital and Udayana University School of Medicine, Bali, Indonesia

\section{End-stage renal disease and hemodialysis in Indonesia} Indonesia is an archipelago comprising 13,466 islands, extending $5120 \mathrm{~km}$ from east to west and $1760 \mathrm{~km}$ from north to south. A total of 8844 of these islands have been named, with 922 of them are permanently inhabited, according to estimates by the government of Indonesia. The five main islands are Sumatra, Java, Kalimantan, Sulawesi, and Papua, and the two major archipelagos are Nusa Tenggara and the Maluku Islands. Indonesia is the world's fourth most populous country after China, India, and the USA, with an estimated population of 260 million as of 2016, which was considerably higher than the 2015 estimate of 257 million. About $56.7 \%$ of Indonesia's population lives on Java, the most populous island (https://en. wikipedia.org/wiki/Geography_of_Indonesia).

Table 9 Demographic data (age and sex) of patients who underwent kidney transplantation under the domestic transplant team in Mongolia

\begin{tabular}{llllll}
\hline Sex & Male & Female & All & & \\
& $92(74.8 \%)$ & $31(25.2 \%)$ & 123 & & \\
Age (years) & $9-20$ & $21-30$ & $31-40$ & $41-50$ & $>50$ \\
Number & $2(1.6 \%)$ & $36(29.3 \%)$ & $49(39.8 \%)$ & $29(23.6 \%)$ & $7(5.7 \%)$ \\
\hline
\end{tabular}

Dialysis therapy was first introduced in 1987, and its use began to increase with the introduction of the hollow fiber dialyzer and dialysis training programs for internists or consultants in nephrology. Today, 358 HD units with 2427 HD machines in Indonesia are available across the islands, but mainly in Java and Sumatra because health facilities and human resources to support the HD units are concentrated there [1]. Ideally, HD units should be run by nephrologists; however, due to a shortage, some HD units are supervised by an internist charged with the responsibility of a nephrologist. The internist would have been trained for 3 months. Typically, the HD unit has visiting nephrologists acting as consultant and supervising nephrologist. In total, 334 HD units are affiliated to hospitals, 154 are government-owned, 151 are private-owned, and the rest are owned by the military and other facilities [1].

The Indonesian Society of Nephrology reports that an estimated 200,000 patients with ESRD need RRT annually. However, due to a shortage of HD machines, not all patients are able to access treatment. In 2014, it was reported that RRT is predominantly HD (82.4\%) followed by CAPD (12.8\%). An increasing trend in incident and prevalent HD patients emerged between 2007 to 2014 (Table 11). Also, the Indonesian Renal Registry (IRR) recorded 4977 incident patients and 1885 prevalent patients in 2007, with 17,193 incident patients and 11,689 prevalent patients by 2014; the highest figures were in 2012 with 19,621 incident patients and 9161 prevalent patients [2]. According to the IRR, the most prevalent etiology of ESRD [2] is hypertensive nephrosclerosis (37\%), followed in order by diabetes mellitus (27\%), chronic glomerulonephritis (10\%), obstructive nephropathy (7\%), and pyelonephritis (7\%). The etiology of kidney failure among dialysis patients in 2014 was mainly ESRD due to CKD (84\%), followed by acute renal

Table 10 Change in numbers of hemodialysis consoles and patients in Mongolia

\begin{tabular}{llllll}
\hline Year & 2011 & 2012 & 2013 & 2014 & 2015 \\
\hline Number of consoles & 46 & 58 & 75 & 92 & 116 \\
Number of patients & 187 & 236 & 332 & 402 & 485 \\
\hline
\end{tabular}


Table 11 Incidence and prevalence of HD from 2007 to 2014 in Indonesia

\begin{tabular}{|c|c|c|c|c|c|c|c|c|}
\hline Year & 2007 & 2008 & 2009 & 2010 & 2011 & 2012 & 2013 & 2014 \\
\hline Incident patients & 4977 & 5392 & 8193 & 9649 & 15,353 & 19,621 & 15,128 & 17,193 \\
\hline Prevalent patients & 1885 & 1936 & 4707 & 5184 & 6951 & 9161 & 9396 & 11,689 \\
\hline
\end{tabular}

insufficiency (9\%) and acute-on-chronic kidney disease (7\%). Regarding comorbidity, the IRR reports that hypertension is the most prevalent (47\%), followed by diabetes mellitus (23\%), cardiovascular disease (7\%), and gastrointestinal disease (7\%). In addition, the most common cause of death was cardiovascular complications (49\%), followed by sepsis (12\%), cerebrovascular disease $(10 \%)$, and gastrointestinal bleeding (4\%) [2]. The most common reasons for cessation of HD were death (49\%) and unknown (25\%) [2].

A total of 234,546 new dialyzers were used in Indonesia in 2014 [2], an approximately 12-fold increase compared with the 18,611 new dialyzers used in 2007. Most dialyzers were reprocessed 1 to 5 times, accounting for 296,586 dialyzers in 2013, a sharp increased from 41,645 in 2007. The frequency of reprocessing 6 to 10 times was lower, accounting for 181,421 dialyzers in 2013, an increase from 15,046 in 2007 (Fig. 3) [2].

There have been reports of dialysis adequacy based on surrogate parameters in a center in Denpasar, Bali. This center reported that with twice weekly dialysis, in patients with targeted KT/V of $\geq 1.8$ or urea reduction ratio $\geq 85 \%$, dialysis adequacy was $36.8 \%$ and $39.0 \%$, respectively. However, in those with serum albumin concentrations $\geq 4 \mathrm{~g} / \mathrm{dL}$, dialysis adequacy was $84 \%$ [2].

A total of 3907 HD patients (2179 [55.77\%] male; 1875 [47.99\%] aged < 50 years) were followed up during a 1-year period. Of all evaluated patients, 1322 died during the 1-year follow-up period, and among them, $87.3 \%, 80.2 \%, 72.3 \%$, $64.6 \%$, and $46.7 \%$ were alive at 1 month, 3 months, 6 months, 9 months, and 12 months of follow-up, respectively. A known risk factor for mortality is age; the IRR reported age $\geq 50$ years as significant (hazard ratio [HR] 1.22; $p<0.001$ ) [2].

The IRR also reported a notable increase in the number of CAPD cases from 1209 in 2012 (1376 in 2013) to 1423 in 2014 as well as in the number of cases of incident CAPD $(n=525)$, withdrawal of CAPD $(n=478)$, and prevalent CAPD $(n=1423)$ in 2014 (Fig. 4) [2].

\section{Healthcare insurance scheme in Indonesia}

Reports from the United States Renal Data System in 2010 show a sevenfold increase in expenditures during the pre-dialysis preparatory period compared with the dialysis period. This cost could be reduced and maintained at only a threefold increase depending on which treatment approach is opted for to delay the progression of CKD [3]. In 2013, the President of the Republic of Indonesia issued Presidential Decree No. 12/2013, as amended by Presidential Decree No. 111/2013, regarding Healthcare Insurance managed by the newly established Healthcare and Social Security Agency (Badan Penyelenggara Jaminan Sosial Kesehatan or "BPJS Kesehatan"). Both the Healthcare Insurance and Workers Social Security schemes are compulsory for all workers. The Healthcare Insurance program is managed by BPJS Kesehatan. Employees are required to participate and contribute to this healthcare scheme. Indonesian citizens and all residents of Indonesia, including long-term expatriates, are required to join. Registration with BPJS covers the whole family. Only one spouse is required to contribute to gain family coverage. The goal is universal coverage for all Indonesians by $2019[4,5]$. This healthcare insurance scheme provides total coverage for dialysis treatment. By 2014, BPJS reported that kidney failure had become the second leading cause of morbidity after heart disease. In the same year, a total of about 2,165,507,578,258 IDR (approximately 161,606,000 USD) worth of insurance claims was made by patients with kidney failure [6]. BPJS funding comes mainly from the national or regional government budget targeting low-income populations, with some coming from the civil service and from public funds as contributions from individuals or private company workers.

\section{Insurance system and dialysis policies}

Funding mostly goes to secondary or tertiary centers that offer dialysis services [7]. HD is a healthcare service characterized by high costs, high volumes, and high risks, so provision of a standardized service developed through evidence-based national clinical guidelines is needed alongside service implementation as standard hospital procedure. This should be supported by well-organized dialysis units and competent human resources. The goals of HD should be good outcomes with reduced mortality and low cardiovascular complications, good nutritional status, and optimal quality of life. These goals may be achieved by targeted $\mathrm{KT} / \mathrm{V}$, maintenance of vascular access, and technology transfer of dialysis machines and dialyzers. Implementation of health technology assessment and anti-fraud regulations for this technology application will lead to cost-effective services in terms of dialysis treatment expenditures [8]. Human resources involved in standard dialysis units (regulated by the Indonesian Society of Nephrology) are nephrologists, internists with at least 3 months of HD training, 


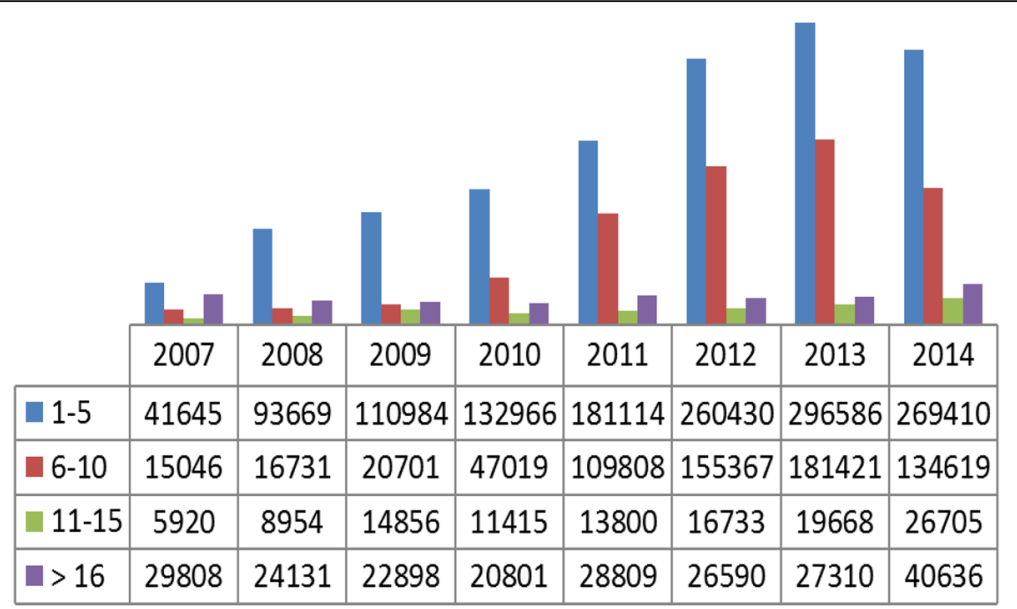

Fig. 3 Reprocessing frequency of dialyzers from 2007 to 2014. Most dialyzers were reprocessed 1 to 5 times

and general practitioners with at least 3 months of HD training $[8,9]$. To update their knowledge and skills, these doctors must participate in continuing professional development in the field of nephrology and dialysis, namely, at the Annual Scientific Meeting of the Indonesian Society of Nephrology. Financial support for HD treatment comes mainly from BPJS (the Healthcare Social Security Agency). Presently, around $60 \%$ of the Indonesian population is covered, with others being supported by regional health insurance, commercial insurance, and fee-for-service. The BPJS is subject to strict regulation by the Health Minister and includes a package system for service claims, a case-mix (INA-CBG) system based on ICD-10 and ICD-11 for diagnosis and procedures, hospital clinical pathways, and quality- and cost-control boards established by BPJS. An anti-fraud regulation has been issued by the Ministry of Health aimed at the prevention and enforcement of anti-fraud measures in medical services, and this includes HD treatment because it is high-technology and high-cost, and most dialysis products are still imported. The INA-CBG package system covers items including service fees, machine and room costs, HD consumables and solutions, drugs and other consumables, blood transfusion, and laboratory and other tests. BPJS also covers surgical procedures for vascular access $[6,10]$. To provide more cost-effective treatment options in the dialysis service, the Ministry of Health conducted a health technology assessment in 2015 to compare cost-effectiveness between HD and CAPD. The Ministry made the following recommendations: (1) HD and PD are complementary to each other with advantages and disadvantages, (2) a PD-first policy that involves offering CAPD to ESRD patients with no

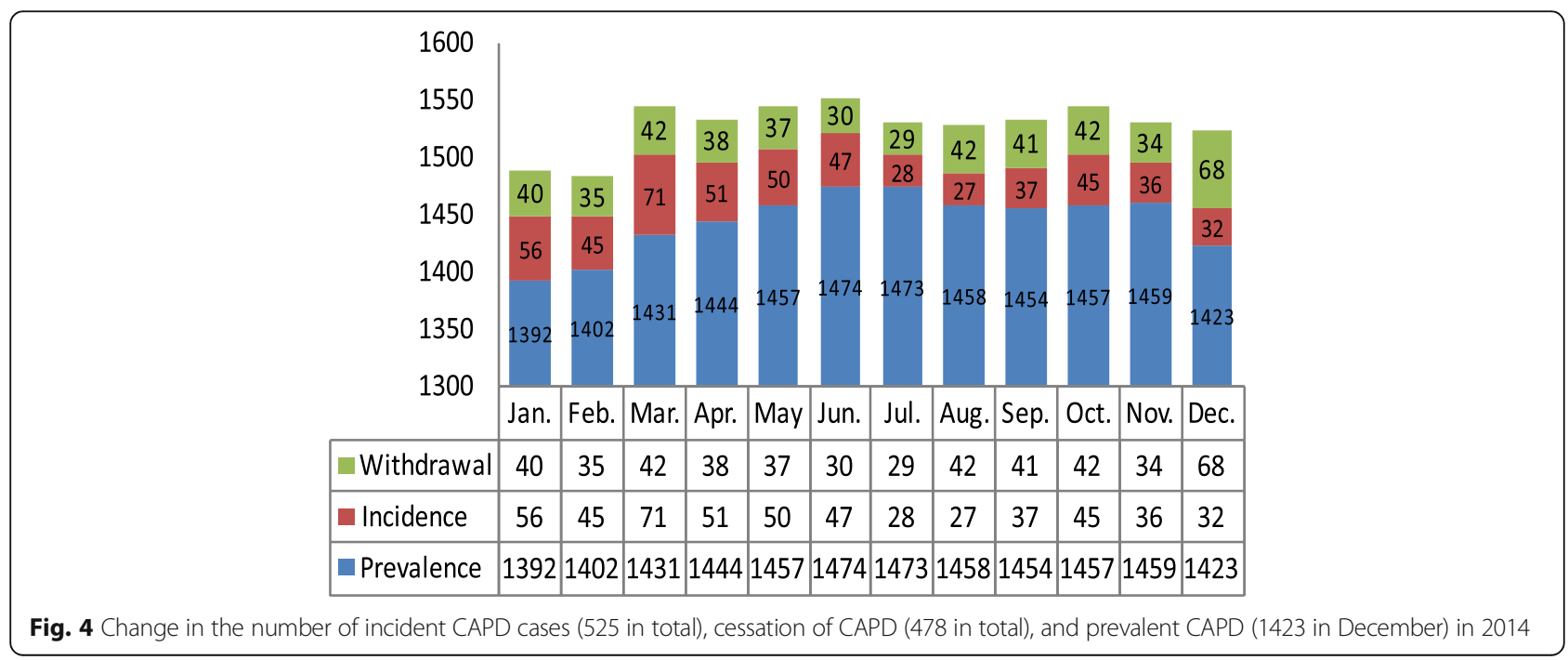


contraindications to the therapy, and (3) the PD-first policy is estimated to conserve about 91.2 trillion IDR over 5 years, with the greatest savings being in the first year. Conversely, HD expenses tend to increase steadily over the years. The Ministry of Health agrees to implement the "PD-first policy" beginning with a pilot program in some regions; the policy is targeted to provide treatment for $30 \%$ of ESRD patients with CAPD by $2019[10]$.

\section{Future challenges of ESRD in Indonesia}

In summary, the challenges facing dialysis treatment in Indonesia are the increasing number of ESRD patients that need regular dialysis and the increasing national economic burden from HD. This may be associated with the increasing prevalence of primary causative diseases, mainly hypertension (37\%) and diabetes mellitus (27\%) (National Health Survey 2013) [2], and total access (universal coverage) to national health insurance. What do we need to overcome these challenges? We need (1) nationwide campaigns and integrated action for prevention in hypertension and diabetes mellitus, (2) early detection through screening programs and prompt treatment of kidney disease, (3) implementation of the PD-first policy as a more cost-effective measure, (4) relocation of manufacturing plants for dialyzers and dialysis solution to Indonesia, and (5) a tax-free policy on imported dialysis goods.

\section{Appendix}

Summary data of the five countries are shown in Table 12.

Table 12 Insurance status and cost of HD (excluding the cost of erythropoietin-stimulating agents, prescription medications, etc.), dialyzer reuse, HD hours per session, and HD sessions per week and numbers of HD and CAPD patients in the five countries

\begin{tabular}{|c|c|c|c|c|c|c|}
\hline Country & $\begin{array}{l}\text { Insurance } \\
\text { and cost } \\
\text { of } \mathrm{HD}\end{array}$ & $\begin{array}{l}\text { Reuse } \\
\text { or } \\
\text { single- } \\
\text { use }\end{array}$ & $\begin{array}{l}\text { HD } \\
\text { hours } \\
\text { per } \\
\text { session }\end{array}$ & $\begin{array}{l}\text { HD } \\
\text { sessions } \\
\text { per } \\
\text { week }\end{array}$ & $\begin{array}{l}\text { No. of } \\
\text { CAPD } \\
\text { patients }\end{array}$ & $\begin{array}{l}\text { No. of } \\
\text { HD } \\
\text { patients }\end{array}$ \\
\hline Cambodia & $\begin{array}{l}100 \% \text { by } \\
\text { patient } \\
\text { (45-60 USD) }\end{array}$ & $\begin{array}{l}\text { Reuse } \\
\text { (6 times) }\end{array}$ & 4 & $\begin{array}{l}1 \text { to } 3 \\
\text { (depends } \\
\text { on patient) }\end{array}$ & $\begin{array}{l}\text { Not } \\
\text { available }\end{array}$ & $\begin{array}{l}\text { 300-500 } \\
\text { (estimated) }\end{array}$ \\
\hline Laos & $\begin{array}{l}100 \% \text { by } \\
\text { patient } \\
\text { (50-70 USD) }\end{array}$ & $\begin{array}{l}\text { Reuse } \\
\text { (5 times) }\end{array}$ & 4 & $\begin{array}{l}1 \text { to } 3 \\
\text { (depends } \\
\text { on patient) }\end{array}$ & 3 & Unknown \\
\hline Bhutan & $\begin{array}{l}100 \% \text { by } \\
\text { government } \\
\text { (30 USD) }\end{array}$ & $\begin{array}{l}\text { Reuse } \\
\text { (3 times) }\end{array}$ & 4 & 2 & $\begin{array}{l}\text { Not } \\
\text { available }\end{array}$ & 150 \\
\hline Mongolia & $\begin{array}{l}100 \% \text { by } \\
\text { insurance } \\
\text { (50 USD) }\end{array}$ & Single-use & 4 & 3 & 9 & 485 \\
\hline Indonesia & $\begin{array}{l}90 \% \text { by } \\
\text { insurance } \\
\text { (70 USD) }\end{array}$ & $\begin{array}{l}\text { Reuse } \\
\text { (see Fig. 3) }\end{array}$ & 4.5 & 2 & 1243 & 11,689 \\
\hline
\end{tabular}

\section{Abbreviations}

BPJS: Badan Penyelenggara Jaminan Sosial Kesehatan; CAPD: Continuous ambulatory peritoneal dialysis; CKD: Chronic kidney disease; ESRD: End-stage renal disease; HD: Hemodialysis; IDR: Indonesian rupiah; IRR: Indonesian Renal Registry; JDWNRH: Jigme DorjiWangchuck National Referral Hospital; JICA: Japan International Cooperation Agency; JSDT: The Japanese Society for Dialysis Therapy; PD: Peritoneal dialysis; PDR: People's Democratic Republic; RRT: Renal replacement therapy; USD: United States dollar

\section{Acknowledgements}

The authors of the report on Cambodian thank the individuals acknowledged in that section.

\section{Funding}

Not applicable

\section{Availability of data and materials Not applicable}

\section{Authors' contributions}

This report is a review article by the Committee of International Communications for Academic Research of the JSDT. TH, MF, NH, and MH designed this report and are committee members. $\mathrm{KN}$ also designed this report and is thr president of the JSDT. All other authors wrote their own reports. All authors read and approved the final manuscript.

\section{Ethics approval and consent to participate}

Our manuscript does not report on or involve the use of any animal or human data or tissue.

\section{Consent for publication}

Written informed consent was duly obtained for the report from Cambodia, which contains personal data. Other reports do not contain personal data.

\section{Competing interests}

The authors declare that they have no competing interests.

\section{Publisher's Note}

Springer Nature remains neutral with regard to jurisdictional claims in published maps and institutional affiliations.

\section{Author details}

${ }^{1}$ The Committee of International Communication for Academic Research of the Japanese Society for Dialysis Therapy, Tokyo, Japan. ${ }^{2}$ The Japanese Society for Dialysis Therapy, Tokyo, Japan. ${ }^{3}$ Cambodia-Japan Friendship Blood Purification Center, Sen Sok International University Hospital, Phnom Penh, Cambodia. ${ }^{4}$ Hemodialysis Center and Department of Nephrology, Mittaphab Hospital, Vientiane, Lao People's Democratic Republic.

${ }^{5}$ Nephrology Unit, Department of Medicine, Jigme Dorji Wangchuck National Referral Hospital, Thimphu, Bhutan. ${ }^{6}$ Nephrology Center, First Central Hospital of Mongolia, Ulaanbaatar, Mongolia. ${ }^{7}$ Division of Nephrology and Hypertension, Udayana University School of Medicine, Bali, Indonesia. ${ }^{8}$ Division of Nephrology and Hypertension, Sanglah General Hospital, Bali, Indonesia.

Received: 1 October 2018 Accepted: 5 March 2019

Published online: 20 March 2019

References

1. http://worldpopulationreview.com/countries/indonesia-population. Fifth report of Indonesian Renal Registry 2012. Indonesian Society of Nephrology.

2. Seventh report of Indonesian Renal Registry 2014. Indonesian Society of Nephrology.

3. United States Renal Data System: 2010. https://www.usrds.org/atlas10.aspx.

4. BPJS Kesehatan: A new medicare system? IES bulletin February 2014 1. IES bulletin, February 2014 KPMG advisory Indonesia.

5. BPJS: Transaction of BOA 2014.

6. Prevention and Law Enforcement System of Fraud in Health Services. Laksono Trisnantoro, Hanevi Jasri, Puti Aulia Rahman. Jakarta: Center of Health Policy and Management Faculty of Medicine University of Gadjah Madan Yogyakarta; 2014. 
7. Guideline on Hemodialysis Services on Health Care Facilities. Directorate of Bina Pelayanan Medik-Specialistik, Directorate General of Bina Pelayanan Medik Ministry of Health 2008.

8. Regulation of Minister of Health Republic of Indonesia Number 812, 2010 About Dialysis Services on Health Care Facilities (Ina).

9. Regulation of Minister of Health Republic of Indonesia Number 36, 2015 About prevention of fraud in the implementation of Health Care Insurance on National Social Security System (Ina).

10. Health technology assessment development in Indonesia: progress and challenges. Health Technology Assessment Commission, Ministry of Heath Republic of Indonesia, 2016.

Ready to submit your research? Choose BMC and benefit from:

- fast, convenient online submission

- thorough peer review by experienced researchers in your field

- rapid publication on acceptance

- support for research data, including large and complex data types

- gold Open Access which fosters wider collaboration and increased citations

- maximum visibility for your research: over $100 \mathrm{M}$ website views per year

At BMC, research is always in progress.

Learn more biomedcentral.com/submissions 